\title{
Exploration of Infiltration Ways of Chinese Education
}

\author{
Lihuan Zhang ${ }^{1, a^{*}, \text { Jie Fan }}{ }^{2, b}$ \\ ${ }^{1}$ Chinese Department, Institute of Humanities, Tianjin University of Finance, Tianjin, China \\ ${ }^{2}$ Library of Tianjin University of Finance, Tianjin, China \\ azhanglihuan1963@163.com, bfanjie@tjufe.edu.cn
}

Keywords: Teaching ways; Chinese education; Library education; Higher education

\begin{abstract}
The rapid development of the society, economy and technologies makes the defects of single talent and knowledge structure become more and more obvious, so it is an important issue of new talent cultivation as how to realize scientific infiltration in talent cultivation. Through the exploration and practice of the infiltrating way of Chinese education and library education, this paper proposes direct infiltration, correlation infiltration, extending infiltration and other infiltration education ways. Ever since the birth of modern education, various reforms of Chinese education have never stopped in China. Recently, because of the appeal for teaching traditional culture and Chinese reform in the college entrance examination, various practices and reflections of Chinese teaching reform have emerged, such as "real Chinese" and "return to the people-oriented Chinese teaching", etc. Actually, Chinese education, regardless of its purpose, is to regard Chinese education as a "holistic education".
\end{abstract}

\section{Extensive Chinese Education Concept and Infiltration Education}

In 1993, the senior high school Chinese teacher Zhang Xiaochun proposed the "extensive Chinese education" ideology system, advocating Chinese education should be centered at classroom teaching and extended to each field of students' lives and combine students' Chinese learning with their school, family and social lives so as to combine "teaching Chinese" with "teaching how to be a virtuous person" and combine teaching Chinese knowledge and developing Chinese capacity with developing intellectual and non intellectual quality. Then, the author proposes the "extensive Chinese education" and "one body with two wings", thinking that classroom teaching should be the main body of Chinese education with extracurricular activities and using Chinese environment as the two wings of classroom teaching so as to motivate each other[1]. This is the demonstration of the holistic education concept.

Infiltration teaching is to infiltrate the contents of certain subject to each subject and break the entire contents of the course of each subject into parts to implement education. [2] This curriculum model facilitates to categorize each aspects of this subject and enables learners to obtain corresponding knowledge, skills and emotions while learning each subject. Modern education calls for more and more interdisciplinary integration and infiltration so as to help students better accept 
and master knowledge through interdisciplinary correlation, form a comprehensive knowledge system and improve their capacity to analyze and solve problems.

In the Internet age, extensive Chinese education should embody the concept of holistic education more and classroom teaching is just a starting point with the responsibility to inspire wisdom, carry forward culture, purify the mind and cultivate aesthetic mind, and it should also lay the foundation of learning concept and learning methods for the subsequent college learning after the freshman year. While the library information retrieval skills have already become the indispensible skill of modern talents, so it is a new topic of the Internet era as how to guide freshmen to learn academic retrieval from online games and Baidu excursion.

\section{Exploration and Practice of Infiltration Ways}

To embed various data and retrieval contents of the library in Chinese classroom teaching is to infiltration library teaching into Chinese education and made students take interest in the dull information retrieval; Introduction to data retrieval of library collection, a case study of Chinese classroom teaching and its related content, in-depth library education is language education to enable students to learn to self education in Chinese, improve the ability of self-renewal. This interdisciplinary infiltration teaching method facilitates students to master knowledge of various disciplines and improve the overall quality and more opportunities for development.

Direct Infiltration and Expand Knowledge. Direct infiltration is to tell students the necessary knowledge in classroom so as to as the retrieval words and teach students how to use relevant database of the library. This is the simplest and directest infiltration way of Chinese teaching and library teaching to find relevant knowledge of classroom teaching and expand students' horizons.

The College Chinese drama unit Germany dramatist Bertolt Brecht of the Caucasian chalk circle, in import of knowledge, teachers have to tell students that it stems from the dramas in the Yuan dynasty Chinese writer Li Qianfu (doers of the word, a line) of the Chalk Circle. Guide the students to use the library's public access system, find related content in the library, in order to understand the origins of the story, context, indescribable way, version changes and so on. Such as "chalk" as a search term in the "title" to retrieve the items and retrieved in the Chinese and foreign famous handed down China Lee Road are included in the volumes of the original text. Students can read the paper. Use Read Show Academic Search for retrieved database to get more results, by era followed by for (Ming) hid Payson followed series Qu selected • ash aperture remember, and 1900 the Chalk Circle, and 1956 Yan Wen adapted Liu Kaishen painted Shanghai culture press ash aperture remember, and 1985 Catherine Chen revisited series Tianjin people art press traditional drama story $\bullet$ ash aperture remember, and 1999 Ding Ruqin authoring Beijing Xinhua press new classical drama classics story series - ash aperture remember, and 2005 adaptation of lilizhangyuan China children's publishing house, China handed down the famous Chinese volume • painted chalk circle, the 2007 adaptation of Catherine Chen revisited Pang Xianjian Tianjin people's fine arts Publishing House, hardcover comic book version of the traditional stories of the chalk circle, 2013 Liu Yanping Jie Ailing Tianjin Education Publishing House of the Chinese Ancient Historical Drama - Stories of Chalk Circle [3]. Thus, students can see that multiple versions (series of books, picture books, comics), various literary forms (drama, story) differences, so as to further understand literature, culture and the relationship between environmental changes with the times.

Correlation Infiltration and Learn to Find Research Clues. Correlation infiltration refers to that during the process of direct infiltrating knowledge, students cannot get relevant information 
through library information retrieval, but they need to reset the retrieval word based on correlation of knowledge so as to obtain the needed information. During this process, students need to learn find the necessary knowledge clues and exercise the basic ability of scientific research.

In the description unit of College Chinese described in the, has sushi paper Dang Valley Yan Bamboo, which introduces painter paper and belongs to Bamboo, directly showing paper and can be of paintings bamboo figure, such both can to students some intuitive of impression, on articles can have deeper of understanding, also can be as courses of expanded points, strengthening the art taste of students. The garden of Chinese Digital Book "China Art Museum" collections can be used when retrieving a database directly using "author" to no avail. Expanding the text associated with the two points--the word "article" and cousin of "sushi", he retrieved the Bamboo [4]. While, if students are interested in the problem, as Bamboo original and the collection status", and "paper and can of painting theory and the features, and research evaluation", and "Song painting of features research", and "sushi of art practice", and "sushi of poetry included and the research", and "idiom of retrieved method", for has teaching expanded, in language education and library education zhiwai associated has art education, received has very good of teaching effect.

Extensive Infiltration and Deepen the Understanding of Teaching Contents. Extended penetration refers to deepen the teaching content, instructional content, characters, plot, involving cultural knowledge necessary to extend the teaching. College Chinese teaching hours is extremely limited, using library books and journals for teachers searching on paper or electronic database searches, second class, by way of preparation, job of guiding students through education. Through this process, deepen students ' understanding of course content. In the study of literary works, realization of edify, cultural heritage, improving the quality of human purpose.

Description unit of the College Chinese, Zuo Jin Son of Chong Er Death excerpt, when introducing Chong er's exile cause, referring to Li Ji Qiren mentioned when Jie zitui live, will bring "Dan King of the cutting unit", "food", "bright". To understand the character, figure out meaning students tend to use "Baidu search", but the information is very fragmentary, high repetition rate, bad authority of literature. Through the mutual infiltration of teaching mode of the library, the librarians giving lectures, refer to course instances, guide the students, using the collection database, access to relevant information, and complete the inquiry process. As the wenyuan Pavilion can be found in the Complete Library in the Four Branches of Literature database Er Zuo Jin Childe in full text, of the death note; the cnki can have relevant academic research papers; the National Quality Curriculum Resource Network can see national courses teaching materials; the Super Star Academic Videos can provide audio and video products, and gradually master the methods of scientific research.

\section{Role and Function of Infiltration Classroom Teaching of Chinese Education and Library Education}

Improve Students' Learning Interests and Strengthen the Learning Effects. In teaching practice, teachers are aware of a single mode of teaching students will be tired, reduce teaching effectiveness. Teachers chalk a book (including take courseware when chalk, blackboard) sitting pontificating, student lectures not only hands-notes, is now a common phenomenon in class. And courseware teaching one class large class of students to listen and take notes before hand and brain, can not be compared with the classroom teacher echo effect, smart phones more student teachers courseware pictures, the Internet provides a convenient private school. 
Language Education and Library Education and infiltrating classroom teaching, you can use your smartphone to make manual students together to achieve positive classroom attention in search of autonomy, increase interest in learning, strengthen teaching. Students listen to the teacher in the classroom language teaching content, follow librarians into the database search, and find themselves under the guidance of the required books librarians on the mobile library service terminal, periodicals related content. Students according to their own situation, feel free to ask, university language teachers and librarians to interact answer, with notes of interest at students' independent teaching content, retrieval method steps.

A novel way to class and the learning ways combining watching, listening, speaking and writing not only improve the students' interest in learning, but also strengthen the classroom teaching.

Deepen Understanding of Knowledge and Expand Horizon. Unrelated knowledge makes students feel trivial, examination-oriented education in students by rote, can't afford to let them set up indicating system. Infiltration in classroom teaching of Chinese education and library education makes students learn links between knowledge in the classroom. Meanwhile, also through the retrieval of knowledge, character, plot and brought in experts, scholars and sages research results, deepening the classroom cognition improved insights and expand students ' knowledge.

In class, students learn about the cultural allusions anecdotes, and holiday makes knowledge become lively and interesting; detached search shows of famous teachers, enabling students to infiltrating traditional literacy and to feel the charm of our forefathers. Infiltration teaching for depth of knowledge, understanding and knowledge is spread wide, is far beyond the traditional teaching.

Lay Foundation for Future Learning and Scientific Researches. High school education, whether it is passive or active, in the final analysis, should be an accepted style of learning. It is reflected in the predecessor to create knowledge and acceptance of cultural and patrimonial. By contrast, university studies are more likely to be research-oriented learnings, whose predecessors have created more reflected in the spirit of knowledge and understanding of the cultural autonomy and creative inheritance. Teaching, teachers opposed $\mathrm{Li}$ "Toshi" learning and do what the container of knowledge. In particular, the electronic media Internet age is even more like this.

Infiltration teaching is actually a primary research site teaching presentations, teaching, more common for librarians teach students how to retrieve knowledge, access to scientific research data, supervise students ' operating skills drills, which enables students to master future courses and postgraduate research study-type learning methods, laying the foundation for future study and research.

\section{References}

[1] Zhang Xiaochun. Main Teaching Modes of "Extensive Chinese Education - Talking about my "Concept of Extensive Chinese Education for the Third Time" [J]. Tianjin Education, 1993,Z1:57-58.

[2]Informationonhttp://baike.baidu.com/link?url=1xfVmtW0Gaf1-hq9NGLWLYbxaw3rM1HyBc6w BA9YHv3Ed19z9VO373ZL1czGoyMGstFPCsrNI1rQvA22_Dhd1_

[3]Information on http://book.duxiu.com/search?sw= $\&$ allsw $=\&$ searchtype $=1 \&$ channel $=$ search $\& b C o n=\&$ ecode $=$ utf $-8 \&$ Field $=1$

[4]Informationonhttp://www.apabi.com/tjdl/?pid=picture.picinfo\&metaid=sa. 0000000000003000001 $1 \& \mathrm{db}=$ picture $\&$ cult $=\mathrm{CN} \& \mathrm{wd}=\% \mathrm{E} 6 \% 96 \% 87 \% \mathrm{E} 5 \% 90 \% 8 \mathrm{C} \& \mathrm{ct}=$ 